\title{
Magnetization Reversal Processes in Pr-Fe-B-type Nanocrystalline Magnets
}

\author{
K. PAWLIK ${ }^{a}$, P. PAWLIK ${ }^{a, *}$, W. KASZUWARA ${ }^{b}$, J.J. WYSEOCKI $^{a}$ \\ ${ }^{a}$ Institute of Physics, Częstochowa University of Technology, Al. Armii Krajowej 19, 42-200 Częstochowa, Poland \\ ${ }^{b}$ Faculty of Materials Science and Engineering, Warsaw University of Technology, \\ Wołoska 141, 02-507 Warszawa, Poland
}

\begin{abstract}
The magnetization reversal processes in magnets derived from rapidly solidified $\mathrm{Pr}_{9} \mathrm{Fe}_{52} \mathrm{Co}_{13} \mathrm{Zr}_{1} \mathrm{Nb}_{4} \mathrm{~B}_{21}$ alloy samples were studied by analysis of minor hysteresis loops and recoil curves. The studies were carried out on suction-cast $1 \mathrm{~mm}$ diameter rod, $1 \mathrm{~mm}$ thick plate, $3 \mathrm{~mm}$ outer diameter (o.d.) tube and melt-spun ribbon samples subjected to annealing at $983 \mathrm{~K}$ for $5 \mathrm{~min}$. The X-ray diffraction analysis has shown multiphase constitution of the samples. Structural and magnetic studies indicated that the initial state of microstructure and phase composition affects the magnetization reversal processes in annealed samples due to a variation of microstructure in samples of various shapes. Magnetic studies allowed estimation of the mean values of nucleation and pinning fields that control the magnetization reversal processes.
\end{abstract}

DOI: 10.12693/APhysPolA.126.186

PACS: $75.50 . \mathrm{Vv}, 75.60 . \mathrm{Ej}, 75.50 . \mathrm{Bb}, 75.50 . \mathrm{Tt}, 75.50 . \mathrm{Ww}$

\section{Introduction}

Recoil curves which are used to determine $M_{r e v}$ vs. $M_{i r r}$ plots can give information about the mechanism of magnetization reversal [1-4]. In some nanocrystalline alloys a collective mechanism is possible [7], in which both pinning [5] and nucleation [6] processes can contribute to the magnetization reversal. Especially, in multiphase magnets, where significant grain size distribution is encountered, and amorphous (or highly disordered) phase is present, the nucleation $\left(H_{N}\right)$ and pinning $\left(H_{p}\right)$ field distributions are expected. Thus the distribution of both $H_{N}$ and $H_{p}$ values can considerably affect the $M_{r e v}$ vs. $M_{\text {irr }}$ relations [3]. Specific microstructure and magnetic properties of multiphase nanocrystalline alloys can also affect the shape of initial magnetization curve $J(H)$ as well as the dependence of coercivity field on the maximum external magnetic field $H_{c}\left(H_{\max }\right)$, measured on initially demagnetized samples [8]. This problem was not widely studied for hard magnets derived from bulk glassy precursors. In the present work the $M_{\text {rev }}$ vs. $M_{\text {irr }}$ relations and $H_{c}\left(H_{\max }\right)$ curves were used to study the differences of magnetic properties in the annealed $\mathrm{Pr}_{9} \mathrm{Fe}_{52} \mathrm{Co}_{13} \mathrm{Zr}_{1} \mathrm{Nb}_{4} \mathrm{~B}_{21}$ alloy samples of various shapes.

\section{Sample preparation}

Bulk samples in the form of: $1 \mathrm{~mm}$ diameter rods, $1 \mathrm{~mm}$ thick plates and $3 \mathrm{~mm}$ outer diameter (o.d.) tubes ( $\sim 0.3 \mathrm{~mm}$ wall thickness) were produced at different cooling rates [9] by suction-casting technique,

\footnotetext{
*corresponding author; e-mail: pawlik@wip.pcz.pl
}

while $30 \mu \mathrm{m}$ thick ribbons were melt-spun from the $\operatorname{Pr}_{9} \mathrm{Fe}_{52} \mathrm{Co}_{13} \mathrm{Zr}_{1} \mathrm{Nb}_{4} \mathrm{~B}_{21}$ alloy. In order to get nanocrystalline microstructure and hard magnetic properties, all samples were annealed at $983 \mathrm{~K}$ for 5 minutes. The X-ray diffractometry (XRD) was used to determine their phase constitution. The series of recoil curves were measured by VSM magnetometry on initially saturated samples as described in [2]. Furthermore, the field dependences of coercivity were determined from minor hysteresis loops measured on initially demagnetized samples.

\section{Results and discussion}

The XRD analysis has shown that in as-cast state the rod and ribbon samples were amorphous while the tube and plate samples were partly crystalline [10]. After annealing all samples were crystalline, however the traces of amorphous matrix were still present [10]. In all annealed samples the main crystalline component was the $\mathrm{Pr}_{2} \mathrm{Fe}_{11.2} \mathrm{Co}_{2.8} \mathrm{~B}$ hard magnetic phase. The paramagnetic $\mathrm{Pr}_{1+x} \mathrm{Fe}_{4} \mathrm{~B}_{4}$ phase was also identified, however positions of peaks corresponding to this phase were not well pronounced, due to the overlapping with peaks coming from $\mathrm{Pr}_{2} \mathrm{Fe}_{11.2} \mathrm{Co}_{2.8} \mathrm{~B}$. In [10] we have confirmed the presence of paramagnetic and disordered phases within the alloy constitution. Furthermore samples of various shapes differed in the fractions of constituent phases. Our TEM studies have shown also the differences in their microstructure. The uniform microstructure, containing grains of mean diameter of $\sim 20 \mathrm{~nm}$ for $1 \mathrm{~mm}$ diameter rod and $60 \mathrm{~nm}$ for the $3 \mathrm{~mm}$ outer diameter tube were found. However in case of plate, a heterogeneous microstructure consisting of $200 \mathrm{~nm}$ grains and agglomerates of nanocrystals with the diameter smaller than $10 \mathrm{~nm}$ was observed [10].

Measurements of hysteresis loops have shown differences in magnetic properties for annealed samples of var- 
ious shapes. The best technical parameters were measured for the annealed tubes, where coercivity $H_{c}$ reached $960 \mathrm{kA} / \mathrm{m}$. With the exception of $1 \mathrm{~mm}$ diameter rod, all annealed samples revealed the remanence enhancement $J_{r} / J_{s}$ that reaches $\sim 0.7$.
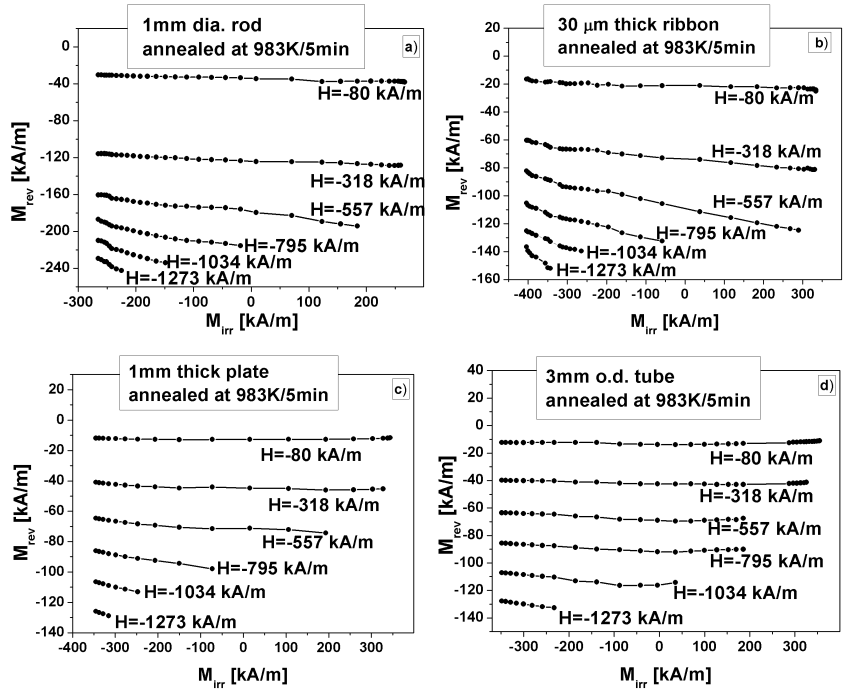

Fig. 1. $M_{r e v}$ vs. $M_{i r r}$ dependences measured for the $\mathrm{Pr}_{9} \mathrm{Fe}_{52} \mathrm{Co}_{13} \mathrm{Zr}_{1} \mathrm{Nb}_{4} \mathrm{~B}_{21}$ alloy samples of various shapes.

The $M_{r e v}\left(M_{i r r}\right)$ for various $H$ are shown in Fig. 1. For rod and ribbon the linear decrease of $M_{\text {rev }}$ with the increase of $M_{i r r}$ suggests that the mean value of nucleation field $H_{N}$ distribution is higher than that of the pinning fields $H_{p}$ [3]. In case of the tube a shallow minimum on $M_{r e v}\left(M_{i r r}\right)$, which occurs for the largest population of domain walls, was revealed. This suggests that the $H_{p}$ distribution has its maximum at higher magnetic fields than that for nucleation fields [11]. For the plate, the $M_{r e v}\left(M_{i r r}\right)$ curves have more shallow minima and quickly turn into straight lines at fields higher than $\sim 500 \mathrm{kA} / \mathrm{m}$. Dependences of coercivity $H_{c}$ on the maximum external magnetic field $H_{\max }$, obtained from the sets of minor hysteresis loops, are presented in Fig. 2. For $H$ lower than $H_{\text {max }} \sim 500 \mathrm{kA} / \mathrm{m}$, low and almost constant values of $H_{c}$ were measured for rods and ribbons. This suggests reversible bowing of pinned domain walls. For larger $H_{\max }$ the domain walls become unpinned and undergo irreversible movement, thus the $H_{c}$ rises. Due to the nucleation of reversed domains at higher fields, the $H_{c}$ does not rise very steeply. Saturation of $H_{c}$ occurs for $H_{\max }$ higher than $1200 \mathrm{kA} / \mathrm{m}$. Steady growth of $H_{c}$, measured for the tube sample at $H_{\max }$ lower than $1000 \mathrm{kA} / \mathrm{m}$, is related to the nucleation of reversed domains, while further increase of $H_{c}$ is due to unpinning of the domain walls at higher $H_{\max }$, also accompanied by nucleation process, as was suggested earlier. More complex $H_{c}\left(H_{\max }\right)$ curve, measured for the $1 \mathrm{~mm}$ thick plate, proves intermediate magnetization reversal process in which both nucleation and pinning processes are equally possible in wide range of $H_{\max }$.

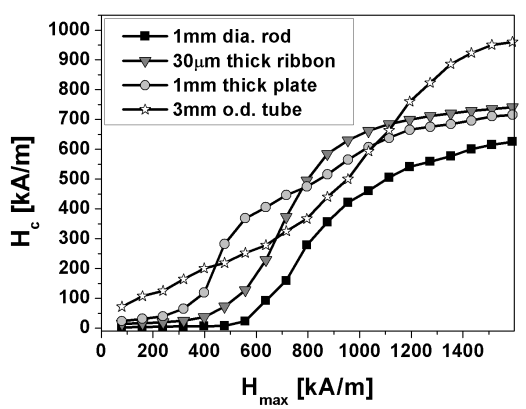

Fig. 2. The dependence of coercivity $H_{c}$ on maximum external magnetic field $H_{\max }$, measured for initially demagnetized samples of the $\operatorname{Pr}_{9} \mathrm{Fe}_{52} \mathrm{Co}_{13} \mathrm{Zr}_{1} \mathrm{Nb}_{4} \mathrm{~B}_{21}$ alloy.

\section{Conclusions}

The shapes of $M_{\text {rev }}\left(M_{i r r}\right)$ for tubes indicate that the magnetization reversal proceeds by nucleation of reversed domain and the subsequent domain wall pinning and bowing. However the $H_{N}$ and $H_{p}$ distributions are widely overlapped. This was confirmed by $H_{c}\left(H_{\max }\right)$ relations. For rod and ribbon the linear decrease of $M_{r e v}\left(M_{i r r}\right)$ suggests that the nucleation mechanism is dominant. For the plate an intermediate mechanism was encountered. Even though the phase composition is similar in samples of various shapes, their microstructure plays important role in the magnetization reversal process.

\section{Acknowledgments}

Work supported by the project N N507 240840 financed by National Science Centre in years 2011-2014.

\section{References}

[1] D.C. Crew, R.C. Woodward, R. Street, J. Appl. Phys. 85, 5675 (1999).

[2] D.C. Crew, P.G. McCormick, R. Street, J. Appl. Phys. 86, 3278 (1999).

[3] D.C. Crew, L.H. Lewis, J. Appl. Phys. 87, 4783 (2000).

[4] D.C. Crew, L.H. Lewis, D.O. Welch, F. Pourarian, J. Appl. Phys. 87, 4744 (2000).

[5] H. Kronmüller, D. Goll, Scripta Materialia 47, 551 (2002).

[6] D. Givord, M.E. Rossignol, D.W. Taylor, Journal de Physique IV 2, C3-95 (1992).

[7] K. Pawlik, P. Pawlik, J.J. Wysocki, W. Kaszuwara, Acta Phys. Pol. A 113, 39 (2008).

[8] K.-D. Durst, H. Kronmüller, J. Magn. Magn. Mater. 68, 63 (1987).

[9] P.Pawlik, K. Pawlik, A. Przybył, Rev. Adv. Mater. Sci. 18, 81 (2008).

[10] K. Pawlik, P. Pawlik, J.J. Wysłocki, W. Kaszuwara, J. Alloys Comp. 536, S348 (2012).

[11] W. Zhang, A. Inoue, J. Appl. Phys. 91, 8834 (2002). 